\title{
Efektifitas Penambahan Intervensi Kinesiotaping Pada Mill's Manipulation Dan Transverse Friction Terhadap Disabilitas Siku Kasus Tennis Elbow Tipe II \\ ${ }^{1} \bowtie$ Syahmirza Indra Lesmana, ${ }^{2}$ Bellani Pebriantika, ${ }^{3}$ Fudjiwati Ichsani \\ ${ }^{1,2,3}$ Fakultas Fisioterapi, Universitas Esa Unggul, Jakarta \\ Jl. Arjuna Utara No.9, RT.1/RW.2, Duri Kepa, Kec. Kb. Jeruk, Kota Jakarta Barat, Daerah Khusus \\ Ibukota Jakarta 11510 \\ Syahmirza.lesmana@esaunggul.ac.id
}

Tanggal Submisi: 16 Desember 2020; Tanggal Penerimaan: 29 Desember 2020

\begin{abstract}
Abstrak
Tujuan: Untuk mengetahui perbedaan efek penambahan kinesiotaping pada intervensi mill's manipulation dan transverse friction terhadap disabilitas siku kasus tennis elbow tipe II. Metode: Penelitian ini merupakan jenis penelitian eksperimental untuk mengetahui disabilitas siku dengan pemberian kinesiotaping pada mill's manipulation, dan transverse friction. Total sampel sebanyak 14 orang yang dipilih berdasarkan teknik purposive sampling dengan menggunakan assesmen yang tersedia. Alat ukur yang digunakan adalah disability of the arm, shoulder, and hand (DASH). Hasil: Hasil uji normalitas dengan shapiro wilk test, sedangkan uji homogenitas dengan independent sample t-test. Hasil uji hipotesis pada kelompok kontrol dengan paried sample t-test didapatkan nilai $\mathrm{p}=0,001$, sedangkan pada kelompok perlakuan dengan paried sample $t$-test didapatkan nilai $\mathrm{p}=0,001$. Pada hasil independent sample t-test menunjukkan nilai 0,003 untuk disabilitas siku yang berarti ada perbedaan efek penambahan intervensi kinesiotaping pada miil's manipulation dan transverse friction terhadap disabilitas siku kasus tennis elbow tipe II. Kesimpulan: Ada perbedaan efektifitas penambahan intervensi kinesiotaping pada mill's manipulation dan transverse friction terhadap disabilitas siku kasus tennis elbow tipe II.
\end{abstract}

Kata Kunci: kinesiotaping, mill's manipulation, transverse friction, tennis elbow type II, dash.

\section{Abstract}

Objective: Determine differences in effect of adding intervensi kinesiotaping on mill's manipulation and tranverse friction to elbow disability case of tennis elbow type II. Method: This study is a quasi exsperimental to determine disability elbow adding intervensi kinesiotaping on mill's manipulation and transverse friction. The total sample is 14 people that chosen from purposive sampling by using the available assesment. The measuring instrument used was disability of the arm, shoulder, and hand (DASH). Result: Results normality test with shapiro wilk test, while homogeneity test with independent sample t-test. The results of hypothesis test in the control group with paired sample t-test $\mathrm{p}$ value $=0,001$, while in the treatment experimental with paired sample t-test $\mathrm{p}$ value $=0.001$. The result of independent sample t-test show $\mathrm{p}$ value $=0,003$ for elbow disability which means giving increase kinesiotaping on mill's manipulation and trasnverse friction to elbow disability case of tennis elbow type II. Conclusion: There differences in effect of adding kinesiotaping on mills manipulation and transverse friction to elbow disability case of tennis elbow type II. 
Keywords: kinesiotaping, mill's manipulation, transverse friction, tennis elbow type II, dash.

\section{PENDAHULUAN}

Dalam upaya meningkatkan kualitas hidup manusia dituntut untuk mengikuti perkembangan zaman. Oleh karena itu, manusia melakukan berbagai aktivitas untuk memenuhi kebutuhan sehari-hari. Di dalam aktivitas kesehariannya manusia selalu melibatkan anggota tubuh, sehingga untuk melakukan segala aktivitas maka manusia harus mempunyai status kesehatan yang baik. Kesehatan merupakan salah satu hal yang sangat penting, karena dalam melakukan aktivitasnya manusia memerlukan kondisi tubuh yang sehat, baik itu sehat secara jasmani atau sehat secara rohani. Menurut World Health Organization (WHO) kesehatan adalah suatu keadaan sehat yang utuh secara fisik, mental, dan sosial bukan hanya bebas dari penyakit.

Ada beberapa aktivitas keseharian yang dilakukan oleh kebanyakan orang adalah dengan menggunakan tangan sebagai alat bantunya. Salah satu fungsi utama tangan adalah untuk menggenggam, seperti menyapu, mencuci, memeras pakaian dan juga pada beberapa jenis olahraga seperti bulu tangkis, golf, dan tennis.

Tennis elbow adalah pembentukan jaringan abnormal pada otot-otot ekstensor pergelangan tangan yang terjadi akibat inflamasi oleh kontraksi yang berlebihan. Keadaan ini akan menimbulkan rasa nyeri, adanya keterbatasan gerak, dan adanya gangguan fungsional yang menyebabkan terhambatnya seseorang dalam melakukan aktivitas sehari-harinya. (Sugijanto dan Partono, 2006). Tennis Elbow banyak terjadi pada tipe II yaitu tendonperiosteal, dimana bila terdapat inflamasi cenderung menjadi kronik. Hal ini disebabkan karena beberapa faktor, antara lain lokasinya merupakan daerah kritis (critical zone) yang sangat miskin pembuluh darah kapiler. Tipe II ini akan mengalami gangguan pada tendon, yang mengalami trauma sehingga menyebabkan inflamasi dari callus maka nyeri tak kunjung hilang, sehingga terjadilah abnormal cross link yang menyebabkan menurunnya kelenturan jaringan dan membuat nyeri regang.
Tennis Elbow memiliki prevalensi 1-3\% pada populasi umum (Bisset et al, 2009), 6-15\% pada pekerja industri(Fedorczyk, 2006) ,19\% pada usia 30-50 tahun lebih dominan wanita (Kaminsky et al, 2003) ,35-42\% pada pemain tennis (Silva, 2008) ,2-23\% pada pekerja umum seperti ibu rumah tangga, aktifitas dengan komputer, pemahat dan mengangkat beban berat (Leclerc et al, 2013).

Secara umum, pasien tennis elbow akan mengeluhkan penurunan kekuatan ketika melakukan gerakan menggenggam, supinasi, dan ekstensi pergelangan tangan. Sekitar sepertiga kasus tennis elbow berhubungan dengan aktivitas hidup sehari-hari. Sehingga menanyakan riwayat pekerjaan dan aktivitas sehari-hari merupakan salah satu hal yang penting dalam menegakkan diagnosis.

Setelah dapat dipastikan menderita Tennis Elbow, maka dapat menentukan intervensi yang tepat untuk mencapai hasil yang efektif dan efisien. Salah satunya yang peneliti berikan adalah Kinesiotaping, Mill's Manipulation, dan Transverse Friction.

Kinesiotaping adalah semacam plester yang di tempel ke kulit yang di maksudkan untuk membantu proses penyembuhan alami tubuh dan untuk menstabilkan otot dan sendi tanpa membatasi ruang gerak sendi dan penguluran dari otot tersebut. Kinesiotaping itu sendiri, tidak membatasi peregangan dari otot yang akan di pasangkan kinesiotaping sehingga tidak akan membatasi gerak atau aktivitas dari seseorang yang menggunakan kinesiotaping (Kase, 2005). Mill's manipulation merupakan bentuk terapi jaringan lunak yang bertujuan untuk pelepasan jaringan yang adhesif, menyearahkan abnormal crosslink yang terbentuk pada tendon tersebut dan merangsang penyembuhan tendon. Dengan menerapkan tekanan dan friction pada area tubuh yang mengalami gangguan myofascial, terapi ini juga untuk memperbaiki jaringan pembungkus otot (Jenings, 2011).Sedangkan Transverse Friction atau deep kompresi merupakan bagian dari manipulasi untuk melepaskan jaringan yang mengalami perlengketan. Dimana dalam 
pengaplikasiannya berupa gerakan yang berlawanan arah dengan serabut suatu jaringan pada tendon atau ligamen, gerakan longitudinal atau melingkar untuk mengurangi spasme otot dan menghilangkan nodulus pada jaringan lunak.

Dari permasalahan tersebut fisioterapi menggunakan alat ukur Disabilities of the Arm, Shoulder, and Hand (DASH). Gangguan pada struktur jaringan spesifik dan gangguan gerak fungsional akan mempengaruhi penurunan aktivitas bekerja, olahraga, rekreasi, serta kualitas hidup. Seperti yang disebutkan dalam DASH kuesioner, tennis elbow dapat mempengaruhi aktivitas seperi menggenggam bola, menggenggam raket, menjinjing tas, menulis, mengetik computer, mencuci pakaian, dan memasak.

\section{METODE PENELITIAN}

Desain penelitian ini bersifat quasi eksperimental. Untuk menguji dan mengetahui efektifitas antara pemberian mill's manipulation dengan transverse friction dan kinesiotaping pada mill's manipulation dengan transverse friction terhadap disabilitas siku kasus tennis elbow tipe II. Desain penelitian yang digunakan adalah pre-test dan post-test grup desain. Penelitian dilakukan kepada dua kelompok sampel penelitian yang dibagi atas kelompok kontrol yang diberikan mill's manipulation dan transverse friction. Sedangkan kelompok perlakuan diberikan kinesiotaping, mill's manipulation, dan transverse friction. Pada kedua kelompok dilakukan pengukuran dengan menggunakan DASH. Hasil dari kelompok kontrol dan kelompok perlakuan dianalisa dan dibandingkan antara kelompok kontrol dan kelompok perlakuan sebelum dan sesudah diberikan intervensi.

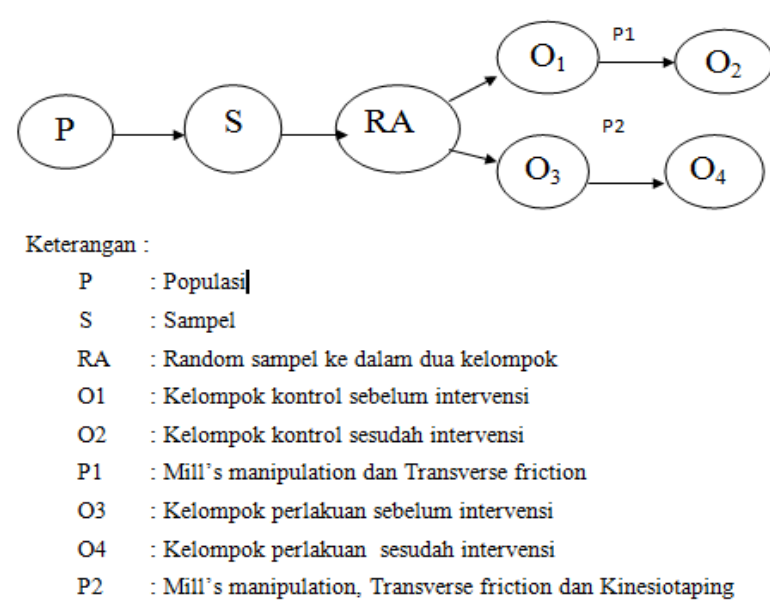

Gambar 1. Gambaran alur penelitian

\section{Hasil Pembahasan}

\section{a. Nilai Disabilitas Siku Pada Kelompok} Kontrol

Pengukuran disabilitas siku pada kelompok kontrol menggunakan dash questionnaire sebelum dan sesudah latihan selama 4 minggu. Nilai penurunan disabilitas dilihat dari nilai pengukuran awal dan nilai pengukuran akhir minggu ke 4. Untuk mengetahui nilai disabilitas siku sebelum dan sesudah pada kelompok kontrol yang diberikan intervensi mill's manipulation dan transverse friction dapat dilihat pada tabel berikut:

\begin{tabular}{cccc}
\multicolumn{4}{c}{ Kelompok Kontrol } \\
\hline & Sebelum & Sesudah & Selisih \\
\hline 1 & 42,24 & 18,96 & 23,28 \\
3 & 35,71 & 11,6 & 24,11 \\
4 & 50,92 & 14,81 & 36,11 \\
5 & 43,51 & 11,11 & 32,4 \\
6 & 53,57 & 18,75 & 34,82 \\
7 & 55,35 & 18,75 & 36,6 \\
Mean & 29,46 & 14,81 & 14,65 \\
SD & 44,39 & 15,54 & 28,85 \\
\hline Sumber data : Data Pribadi
\end{tabular}

Gambar 2. Nilai Pengukuran Disabilitas Siku Kelompok Kontrol 


\section{b. Nilai Disabilitas Siku Pada Kelompok Perlakuan}

Pada kelompok perlakuan data nilai penurunan disabilitas siku sebelum dan sesudah diberikan intervensi kinesiotaping, mill's manipulation, dan transverse friction dapat dilihat pada tabel 1 berikut :

Tabel 1. Nilai Pengukuran Disabilitas Siku Kelompok Perlakuan

\begin{tabular}{|c|c|c|c|}
\hline \multicolumn{4}{|c|}{ Kelompok Perlakuan } \\
\hline & Sebelum & Sesudah & Selisih \\
\hline 1 & 62,93 & 28,44 & 34,49 \\
\hline 2 & 45,31 & 21,29 & 24,02 \\
\hline 3 & 60,34 & 29,31 & 31,03 \\
\hline 4 & 47,41 & 18,96 & 28,45 \\
\hline 5 & 50,86 & 18,96 & 31,9 \\
\hline 6 & 51,85 & 21,29 & 30,56 \\
\hline 7 & 53,7 & 23,14 & 30,56 \\
\hline Mean & 53,2 & 23,05 & 30,14 \\
\hline SD & 6,44 & 4,24 & 3,25 \\
\hline
\end{tabular}

\section{c. Uji Normalitas dan Uji Homogenitas}

Untuk mengetahui apakah sampel dari populasi yang telah diperoleh berdistribusi normal, maka digunakan uji normalitas dengan menggunakan uji Shapiro Wilk Test yang dapat dilihat pada tabel 2 berikut :

Tabel 2. Hasil Uji Normalitas

\begin{tabular}{|c|c|c|c|c|c|}
\hline & & \multicolumn{4}{|c|}{ Saphiro Wilk Test } \\
\hline & & $\begin{array}{c}\mathrm{P} \\
\text { Sebelum }\end{array}$ & $\begin{array}{c}P \\
\text { Sesudah }\end{array}$ & Selisih & Keterangan \\
\hline Disabilitas & $\begin{array}{c}\text { Kelompok } \\
\text { Kontrol }\end{array}$ & 0,652 & 0,113 & 0,203 & Nomal \\
\hline (DASH) & $\begin{array}{l}\text { Kelompok } \\
\text { Perlakuan }\end{array}$ & 0,638 & 0,126 & 0,458 & Normal \\
\hline
\end{tabular}

Dalam penelitian ini untuk melihat homogenitas data penelitian atau nilai disabiltas siku antara kelompok kontrol dan kelompok perlakuan, peneliti menggunakan uji Levene's Test. Hasil uji homogenitas dengan uji Levene's Test dapat dilihat pada table 3 berikut:
Tabel 3. Uji Homogenitas

\begin{tabular}{cccc}
\hline & Sebelum & Levene's test & Keterangan \\
\hline Kelompok Kontrol & $44,39=9,58$ & \multirow{2}{*}{0,270} & Homogen \\
Kelompok Perlakuan & $53,2 \pm 6,44$ & & \\
\hline Sumber data : Data Pribadi & &
\end{tabular}

Berdasarkan tabel 3 didapat nilai $p$ kelompok kontrol sebelum intervensi adalah 0,652 dimana sampel berdistribusi normal, kelompok kontrol sesudah intervensi 0,113 dimana sampel berdistribusi normal. Dan nilai $\mathrm{p}$ kelompok perlakuan sebelum intervensi adalah 0,638 dimana sampel berdistribusi normal, kelompok perlakuan sesudah intervensi 0,126 dimana sampel berdistribusi normal. Selisih kelompok kontrol sebelum dan sesudah intervensi 0,203 dimana sampel berdistribusi normal, selisih kelompok perlakuan sebelum dan sesudah intervensi 0,458 dimana sampel berdistribusi normal. Dan nilai p pada tabel 3 adalah 0,270 dimana sampel homogen.

\section{Pengujian Hipotesis}

Uji hipotesis yang digunakan pada penelitian ini menggunakan uji paired sample t-test untuk menentukan ada tidaknya perbedaan nilai disabilitas siku sebelum dan sesudah pada kelompok kontrol dan kelompok perlakuan. Selain menggunakan uji diatas, juga digunakan uji independent t-test untuk mengetahui ada tidaknya perbedaan nilai disabilitas siku yang didapat dan nilai selisih sebelum dan sesudah latihan pada kelompok kontrol dan kelompok perlakuan.

\section{Uji Hipotesis I}

Untuk menguji signifikasi dua sampel yang saling berpasangan pada kelompok kontrol dengan menggunakan paried sample ttest . Dengan pengujian hipotesa Ho diterima bila nilai $\mathrm{p}>\alpha(0,05)$, sedangkan Ho ditolak bila nilai $\mathrm{p}<\alpha(0,05)$. Untuk mengetahui pengaruh pemberian mill's manipulation dan transverse friction terhadap penurunan disabilitas siku, maka dilakukan uji statistik menggunakan paried sample t-test. 
Tabel 4. Distribusi Nilai Fungsional Wrist degan DASH

\begin{tabular}{lccc}
\hline & Sebelum & Sesudah & P \\
\hline Kelompok Kontrol & $44,39 \pm 9,58$ & $15,54 \pm 3,37$ & 0,000 \\
Kelompok & $53,2 \pm 6,44$ & $23,05 \pm 4,24$ & 0,000 \\
Perlakuan & & & \\
\hline Sumber data : Data Pribadi & &
\end{tabular}

Dari tabel 4 terlihat bahwa nilai mean disabilitas siku pada kelompok kontrol sebelum latihan sebesar 44,39 $\pm 9,58$ dan nilai mean sesudah latihan sebesar 15,54 $\pm 3,37$. Berdasarkan hasil paired sample t-test dari data tersebut didapatkan nilai $\mathrm{p}=0,001$ dimana nilai $\mathrm{p}<$ nilai $\alpha(0,05)$. Hal ini berarti Ho ditolak, sehingga dapat disimpulkan bahwa ada efek Mill's manipulation dan transverse friction terhadap disabilitas siku pada tennis elbow tipe II.

\section{Uji Hipotesis II}

Untuk menguji signifikasi dua sampel yang saling berpasangan pada kelompok perlakuan, dengan data terdistribusi normal maka di gunakan uji parametrik yaitu paired sample test. Dari tabel 4.6 terlihat bahwa nilai mean fungsional wrist pada kelompok perlakuan sebelum latihan sebesar $53,2 \pm 6,44$ dan nilai mean sesudah latihan sebesar $23,05 \pm 4,24$. Berdasarkan hasil paired sample t-test dari data tersebut di dapatkan nilai $\mathrm{p}=0,001$ dimana nilai $\mathrm{p}<$ nilai $\alpha(0,05)$. Hal ini berarti Ho ditolak, sehingga dapat disimpulkan bahwa ada efek Mill's manipulation, transverse friction, dan kinesiotaping terhadap disabilitas siku pada tennis elbow tipe II.

\section{Uji Hipotesis III}

Untuk menguji signifikasi dua sampel yang saling berpasangan pada kelompok kontrol dan kelompok perlakuan, dengan data terdistribusi normal maka di gunakan uji parametrik yaitu independent sample t-test. Didapat hasil bahwa nilai mean sesudah pada kelompok kontrol sebesar 15,54 $\pm 3,37$ dan nilai mean sesudah pada kelompok perlakuan sebesar 23,05 $\pm 4,24$. Berdasarkan hasil independent sample t-test dari data tersebut di dapatkan nilai $\mathrm{p}=0,003$ dimana nilai $\mathrm{p}<$ nilai $\alpha$ $(0,05)$. Hal ini berarti Ho ditolak, sehingga dapat disimpulkan bahwa ada perbedaan efek antara Mill's manipulation, dan transverse friction dengan Mill's manipulation, transverse friction, dan kinesiotaping terhadap disabilitas siku pada tennis elbow tipe II.

\section{Pembahasan}

Berdasarkan hasil penelitian yang telah dilakukan selama 4 minggu di perumnas 3 an jumlah sampel 14 orang yang terbagi menjadi dua kelompok yaitu kelompok kontrol dan kelompok perlakuan yang masing-masing berjumlah 7 orang. Dimana pada kelompok kontrol diberikan mill's manipulation dan transverse friction, dan pada kelompok perlakuan diberikan kinesiotaping pada mill's manipulation dan transverse friction. Hasil penelitian ini akan menjawab hipotesa yang terdapat pada bab sebelumnya dengan pejelasan sebagai berikut :

1. Hipotesa I : mill's manipulation dan transverse friction dapat menurunkan disabilitas siku pada tennis elbow tipe II.

Hasil penelitian skripsi ini, dimana pada kelompok kontrol terdiri dari 7 orang sampel dan diberikan Mill's manipulation dan transverse friction. Nilai disabilitas siku diukur dan dievaluasi dengan menggunakan instrument DASH. Berdasarkan bab sebelumnya, diketahui mean dan standar deviasi disabilitas siku sebelum pemberian Mill's manipulation dan Transverse Friction 44,39 $\pm 9,58$, sedangkan sesudah pemberian Mill's manipulation dan Transverse Friction 15,54 $\pm 3,37$. Hasil paried sample t-test didapatkan p-value 0,001 ini menunjukan nilai $p<\alpha(0,05)$ yang berarti Ho ditolak dan Ha diterima, yang berarti pada kelompok kontrol terdapat penurunan disabilitas siku yang siginfikan antara sebelum dan sesudah pemberian Mill's manipulation dan Transverse Friction.

Pada kelompok kontol penurunan tertinggi terdapat pada sampel nomor 3 dengan nilai sebelum diberikan intervensi yaitu 50,92, sedangkan nilai sesudah diberikan intervensi yaitu 14,81, dimana selisih penurunan disabilitas yaitu 36,11 . 
Sedangkan penurunan terendah terdapat pada sampel nomor 7 dengan nilai sebelum intervensi yaitu 29,46, sedangkan nilai sesudah diberikan intervensi yaitu 14,81, dimana selisih penurunan disabilitas yaitu 14,65.

Menurut jurnal dengan judul "Effectiveness of Cyriax Physiotherapy in Subjects with Tennis Elbow" memberikan kesimpulan bahwa Mill's manipulation yang menyebabkan peningkatan kerusakan dari sakit yang akan memprovokasi metabolik seperti zat Lewis. Mekanisme lainnya dimana pengurangan nyeri mungkin dicapai adalah melalui disebarkannya kontrol penghambatan yang merugikan, mekanisme dari rasa sakit yang melepaskan opiat endogen.

Dan jurnal "The Effect of Deep Friction Massage versus Stretching of Wrist Extensor Muscles in the Treatment of Patients with Tennis" bahwa pasien yang dilakukan terapi dengan transverse friction menunjukkan bahwa ada yang signifikan pada peningkatan ROM fleksi pergelangan tangan dan ekstensi pergelangan tangan, dan handgrip tetapi tidak begitu signifikan dalam penurunan nyeri. Penelitian ini menunjukkan bahwa latihan peregangan lebih bermanfaat dalam penatalaksanaan pasien dengan tennis elbow. Dari penelitian dan jurnal diatas maka disimpulkan bahwa efek Mill's manipulation dan transverse friction dapat diterima dan memiliki efek yang signifikan pada tennis elbow tipe II.

2. Hipotesa II : mill's manipulation, transverse friction, dan kinesiotaping dapat menurunkan disabilitas siku pada tennis elbow tipe II.

Pada penelitian ini, kelompok perlakuan terdiri dari 7 orang sampel dan diberikan penambahan intervensi kinesiotaping pada Mill's manipulation dan transverse friction. Nilai disabilitas siku diukur dan dievaluasi dengan menggunakan instrument DASH. Berdasarkan dari tabel 4.3 pada bab sebelumnya, diketahuin mean dan standar deviasi disabilitas siku kelompok perlakuan sebelum pemberian intervensi kinesiotaping, Mill's manipulation dan transverse friction 53,2 $\pm 6,44$, sedangkan sesudah pemberian kinesiotaping, Mill's manipulation dan transverse friction adalah $23,05 \pm 4,24$. Hasil paired sample $t$ test didapatkan p-value 0,001 ini menunjukan nilai $\mathrm{p}<\alpha(0,05)$ yang berarti Ho ditolak dan Ha diterima, yang berarti pada kelompok perlakuan terdapat penurunan disabilitas siku yang sangat siginfikan antara sebelum dan sesudah pemberian kinesiotaping, Mill's manipulation dan transverse friction.

Pada kelompok perlakuan penurunan tertinggi terdapat pada sampel nomor 1 dengan nilai sebelum diberikan intervensi yaitu 62,93, sedangkan nilai sesudah diberikan intervensi yaitu 28,44, dimana selisih penurunan disabilitas yaitu 34,49. Sedangkan penurunan terendah terdapat pada sampel nomor 2 dengan nilai sebelum intervensi yaitu 45,31, sedangkan nilai sesudah diberikan intervensi yaitu 21,29, dimana selisih penurunan disabilitas yaitu 24,02. Hal ini terjadi karena pemberian kinesiotaping terhadap tennis elbow dapat merangsang atau memfasilitasi beberapa proses fisiologi tubuh manusia, seperti meningkatkan fungsi otot, menurunkan tonus otot, melancarkan aktivitas sistem limfatik, dan mekanisme analgesic endogen serta meningkatkan mikrosirkulasi. Hal tersebut dikarenakan kinesiotaping akan mengangkat kulit dan memberikan ruang pemisah antara kulit dengan otot, serta meningkatkan aktivitas propioseptif melalui kulit untuk menormalisasikan tonus otot, mengurangi nyeri (Kuntono, 2014).

Dalam jurnal "Effects of Kinesiotaping in patients with symptoms of lateral epicondylalgia" memberikan kesimpulan bahwa pemasangan kinesiotaping efektif sebagai fasilitasi pada pasien epicondylitis lateral sehingga menurunkan nyeri dan 
memperbaiki fungsi yang dinilai menggunakan kuesioner sederhana. Hal ini sejalan dengan hasil penelitian yang dilakukan dengan adanya penurunan disabilitas siku yang signifikan pada pemberian intervensi kinesiotaping pada Mill's manipulation dan transverse friction terhadap penurunan disabilitas siku kasus tennis elbow tipe II.

3. Hipotesa III : Ada perbedaan efek penambahan intervensi kinesiotaping pada Mill's manipulation dengan transverse friction dan intervensi Mill's manipulation dengan transverse friction terhadap disabilitas siku kasus tennis elbow tipe II.

Setelah diberikan intervensi antara kelompok kontrol dan kelompok perlakuan. Dengan masing-masing kelompok sampel yang berbeda dan tingkat yang berbeda pula, hal ini berkaitan dengan tingkat usia serta aktivitas sampel yang berbeda-beda. Dari semua sampel dari tiap kelompok pada minggu ke 4 hasil pengukuran menunjukan adanya peningkatan. Hal ini dikarenakan pemberian mill's manipulation yaitu untuk melepaskan adhesion pada cidera yang terjadi pada tendon dan otot dengan reaksi regangan secara lambat dan bertahap, otot akan memberikan respon neurofisiologis atau mekanikal yaitu golgi tendon akan terstimulasi dan menginhibisi tegangan otot sehingga pemanjangan pada komponen elastik otot (sarcomer). Peregangan yang dilakukan akan menghasilkan stress longitudinal pada serabut otot sehingga dapat memobilisasi (Jeffrey S. Brault et al, 2001). Dan pemberian transverse friction untuk mengurangi nyeri kronik melalui stimulus tipe saraf A-delta dan $\mathrm{C}$ untuk modulasi nosisensor dijaringan lunak serta melepaskan perlengketan jaringan lunak akibat kontraktur dan atau nodulus. Dengan massage berupa friction dapat melancarkan sirkulasi darah secara lokal. Pada tingkat supra spinal terjadi counter irritation dimana adanya pelepasan endorfin sehingga dapat mengurangi atau mereduksi rasa nyeri. Pemberian deep transverse friction pada jaringan otot dapat mencegah terbentuknya atau melepaskan perlengketan jaringan yang terbentuk pada serabut otot. Sedangkan pemberian kinesiotaping akan didapatkan efek lifting yang akan mengurangi kompresi pada ujung saraf sensori (sensory nerve ending) sehingga tranduksi nyeri berkurang. Memberikan inhibisi pada otot yang mengalami spasme akibat nyeri lateral epicondylitis (otot extensor carpi radialis), sehingga otot dapat melakukan aktivitas tanpa menimbulkan rasa nyeri. Dan memberikan koreksi fasia dan koreksi space yang mempunyai efek terhadap pengurangan nyeri melalui analgesic endogen system dan meningkatkan fleksibilitas kolagen fasia menjadi lentur.

Hasil yang didapat pada penelitian ini adalah terdapat perbedaan penurunan disabilitas siku pada kasus tennis elbow tipe II antara kelompok kontrol yang diberikan mill's manipulaton dengan transverse friction dan kelompok perlakuan yang diberikan kinesiotaping pada mill's manipulation dan transverse friction. Dimana pemberian kinesiotaping pada mill's manipulation dan transverse friction lebih berpengaruh dari pada mill's manipulation dan transverse friction terhadap disabilitas siku pada kasus tennis elbow tipe II. Sehingga pada akhir penelitian ini terlihat bahwa nilai mean dan standar deviasi sesudah disabilitas siku kelompok kontrol 26,60 $\pm 3,4$, sedangkan pada kelompok perlakuan $23,05 \pm 4,24$. Berdasarkan hasil penurunan disabiltas siku yang di peroleh dari kedua kelompok tersebut tersebut, memiliki perbedaan hasil dengan nilai $\mathrm{p}=0,003$ dimana nilai $(\mathrm{p}<0,05)$.

\section{KESIMPULAN}

Berdasarkan uraian hasil penelitian diatas, maka dapat disimpulkan bahwa Ada perbedaan efektivitas penambahan antara mill's manipulation dengan transverse friction dan 
kinesiotaping pada mill's manipulation dengan transverse friction terhadap disabilitas siku kasus tennis elbow tipe II.

\section{DAFTAR PUSTAKA}

Bisset, L., Paungmali A, Vicenzino B, Beller E. 2009. A systematic review and metaanalysis of clinical trials on physical intervention for lateral epicondylitis. Australia : British Journal of Sports Medicine (BMJ Journals) ; 39 (7)

Fedorczyk, JM. 2006. Tennis Elbow: Blending Basic Science With Clinical Practice. Journal of Hand Therapy.

Fornalski, Stefan., Ranjan Guptan, Thay Q. Lee. 2003. Anatomy and Biomechanics of the Elbow Joint. Philadelphia: Lippincott Williams \& Wilkins, Inc.; 7 (4): 168-178

Hasan Mahmoud Sahar, Hafez Ramadhan Ashraf, Seif Eid Hamada, Kachanathu John Shaji. 2016. The Effect of Deep Friction Massage versus Stretching of Wrist Extensor Muscles in the Treatment of Patients with Tennis. Open Journal Of Therapy and rehabilitation

Hertling, Darlene, Randolph M. Kessler. 2006. Management of common muskuluskeletal disorder Physical therapy Principles and methods Fourth edition. Philadelphia : Lippincott Williams \& Wilkins. Page: 357-361

Janikowska Karolina, Fidut Joanna. 2013. Effects of Kinesio taping in patients with symptoms of lateral epicondylalgia.

Jeffrey S. Brault, Robert E. Kapller, dan Brian E. Grogg. 2001. Manipulation, Traksi, and Massage USA : book Kappler.

Kaminsky, SB., Baker CL, Baker. 2003. Lateral epicondylitis of the elbow.; 7 (4): 179-89

Kase, K. ,D.C. (2005). Illustrated Kinesio Taping Fourth Edition : page 8-14. Tokyo.

Kisner Carolyn, Colby Lynn A. 2007. Therapeutic Exercise Foundations and Techniques Fifth Edition. Philadelphia : F. A. Davis Company
Leclerc, Annette., Marcel Goldberg, Catherine. 2013. Work-related risk factors for incidence of lateral epicondylitis in a large working population.

MA, Reicher., Resnick D., Mc Dade W. 2010. Lateral epicondylitis : correlation of $M R$ imaging, surgical and histopathology.

Maggs. Tim, 2005 Kinesio-taping at keeping injuries managed Arkansas : isokinetics.

Muro, F.G. , Fernandez,L.R. , Lucas,H.D. (2009, September). Treatment of myofascial pain in the shoulder with Kinesio Taping. A case report. Department of Physiotherapy, Faculty of Medicine, CEU-San Pablo University, C/Tutor, 35, 28008. Madrid, Spain.

Pocock., 2008. Clinical Trial. A Practical Approach. New York : A Willey Medical Publication.

Silva, Anderson. 2008. Treatment of tennis elbow.

Sugijanto dan Partono, Muki. 2006. Pengaruh Penambahan Transverse Friction pada Intervensi Ultra Sound Terhadap Pengurangan Nyeri Akibat Tennis Elbow Tipe II. Jurnal Fisioterapi Indonusa vol 6 no 2, hal 117.

Tepe, Rodger. (2011, April). Kinesio Tape's Effect on Musculature Associated. Chesterfield, Missouri, U.S.

Vicenzino, Bill. 2003. Lateral epicondylalgia: a musculoskeletal physiotherapy perspective. Manual Therapy.; 8 (2) : 6679.

Viswas Rajadurai, Ramachandran, Rejeeshkumar, Anantkumar Korde Payal. 2012. Comprasion of Effectiveness of Supervised Exercise Program and Cyriax Physiotherapy in Patients with Tennis Elbow (Lateral Epicondylitis): A Randomized Clinical Trial. The Scientific World Journal : Mumbai, India.

World Health Organization, 2001 Programmes and Projects : International Classification of Functioning, Disability and Health (ICF), accessed 28 Februari 2016. 